This item was submitted to Loughborough's Research Repository by the author.

Items in Figshare are protected by copyright, with all rights reserved, unless otherwise indicated.

\title{
Building services component reuse: an FM response to the need for
} adaptability

PLEASE CITE THE PUBLISHED VERSION

http://dx.doi.org/10.1108/02632779710188306

PUBLISHER

(C) MCB University Press (now Emerald)

VERSION

AM (Accepted Manuscript)

LICENCE

CC BY-NC-ND 4.0

REPOSITORY RECORD

Webb, Roy S., John R. Kelly, and Derek S. Thomson. 2019. "Building Services Component Reuse: An FM Response to the Need for Adaptability". figshare. https://hdl.handle.net/2134/9656. 
This item was submitted to Loughborough's Institutional Repository (https://dspace.lboro.ac.uk/) by the author and is made available under the following Creative Commons Licence conditions.

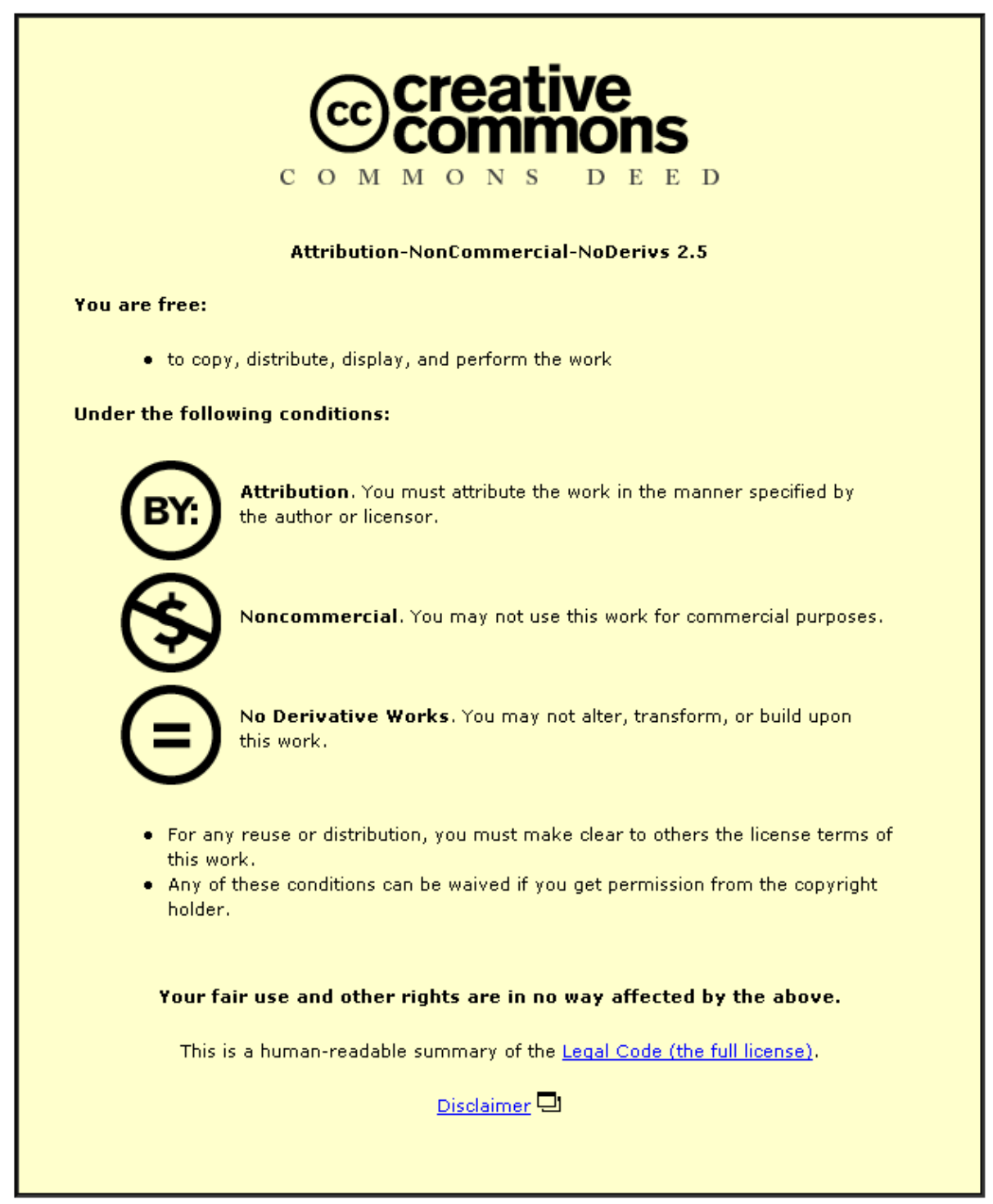

For the full text of this licence, please go to: http://creativecommons.org/licenses/by-nc-nd/2.5/ 


\title{
Building Services Component Reuse: An FM Responses to the Need for Adaptability
}

Roy S. Webb, John R. Kelly, Derek S. Thomson

\begin{abstract}
This paper proposes that facilities managers can viably utilise building services components that have been designed to be more readily reused to satisfy growing client demands for adaptable buildings. In an increasingly dynamic business environment, many organisations seeking to remain competitive have focused on performing their core function in the short-term by shedding, amongst other functions, responsibility for their supporting buildings to external organisations. The growth of the facilities management support industry illustrates this trend.
\end{abstract}

The increasing contribution of services installations to building complexity and value means that the greatest opportunity for facilities managers to improve their efficiency in satisfying constantly changing client space use demands lies in their management of this building element. By utilising reusable services components, facilities managers may be able to increase the adaptability of both new and existing buildings and reduce the financial impact of change.

It is concluded that a new industrial sector may emerge to support services component reuse. This sector will undertake the remanufacture (reconditioning) of such component to ensure their fitness for purpose for reuse.

\section{Keywords:}

Building services components; reuse; facilities management; reconditioning; remanufacture; healthcare; performance specification.

\section{Introduction}

The interaction of a number of influences such as rising consumer expectations, the increasing rate of technological progress and intensifying competitiveness creates markets for goods and services that continually change their function. This market dynamism restricts the ability of businesses to programme their operation over the long term causing many to respond by developing more market-led roles, focused on the performance of their core function in the short-term.

The structure and influences acting on the NHS internal market for healthcare services mirror market function in the general business environment. The NHS therefore provides an appropriate surrogate for many business sectors in the development of new tools and techniques that can be used by facilities managers in their management of buildings that must respond to the dynamic 
environment in which their users operate. As healthcare buildings typically possess extensive and complex building services installations, it is considered most advantageous to initially develop services component reuse in this sector. This proposal focuses on the creation of flexible services installations to service building spaces undergoing changes of use in the shortterm. This will be achieved by utilising services components that have been designed to accommodate reuse, facilitated by their remanufacture (reconditioning), possibly by a new industrial sector, and the provision of warranties.

Adaptation of serviced building spaces typically results in the stripping of associated services installations from buildings and disposal of components as scrap. With an anticipated future increase in the frequency of building adaptation the likelihood is that more services components will become functionally - rather than economically or physically - redundant corresponding with a reduction in the duration of their application. These functionally redundant components retain a significant residual physical life and potential for future use. Due to their embodied residual physical life and un-depreciated capital investment the potential value of such components, if recovered for reuse, is likely to be substantially higher than if they are disposed of as scrap in accordance with current practice. As the construction industry cannot afford to dispose of components with such attributes in this manner it is considered detrimental to the effectiveness of facilities management to continue this practice in the future. By implementing the reuse of services components facilities managers can recover a higher residual component value upon functional redundancy.

\section{Business Response to Market Dynamism}

The environment in which businesses function is continually changing. In recent years the dynamism of business markets has been increasing and will likely continue to do so in the future. Businesses wishing to be successful must be flexible in their operation as continual evolution of their environment increases the likelihood of previously proven business strategies becoming invalid (Willis, 1992).

In response to this need for flexibility, businesses often optimise their operation by separating core function (those activities which the business was established to perform) from non-core, supporting, functions (those activities that business undertakes to facilitate performance of its core function). Shedding managerial responsibility for non-core functions by outsourcing appropriate expertise allows businesses to focus on performing their core function in a more market responsive, flexible manner by focusing on the short-term.

A function for which businesses commonly outsource expertise is the management of supporting buildings. Growth of the facilities management support industry is representative of this business trend to externalise responsibility for the performance of supporting activities.

\section{The Influence of the Changing Business Environment on NHS Function}

The now largely complete NHS reform process was instigated by the "Working for Patients" Government White Paper (Department of Health, 1989) which stipulated that the NHS be remodelled on the general business environment. The objectives of this reform were to improve efficiency and the quality of care available to patients by introducing market function. As the 
current NHS structure mirrors that of the general business environment, assets such as buildings are utilised in a similar manner to those supporting industrial activity (Pearce, 1989).

The characteristic business-like function of the NHS in its current form is centred around the internal market for healthcare services that mirrors the dynamism of the general business environment. A number of inter-linked influences act on this market (Anon., 1993, Pitt, Griffith, 1995) and, although different from those present in the general business environment, necessitate healthcare provider flexibility in terms of healthcare services output. As with business generally, NHS Trusts are tending to focus on the performance of their core function in the short-term.

\section{The Use of Facilities Management by the NHS}

Increasing utilisation of facilities management practices by the NHS has emerged for two reasons. In the first instance, the NHS itself has developed facilities management capabilities by evolving its traditional estate practices (Alexander, 1993). Secondly, compulsory competitive tendering has introduced commercial facilities management organisations to the NHS where market testing has identified that they offer better value for money (Department of Health, 1996). NHS appreciation of the benefits of a facilities approach to the management of buildings is embodied in available management guidance material, for example (Department of Health, 1996):

"Facilities management provides a framework for the effective management of change. It adds value to a business by releasing management time and reorganising resources to meet business objectives"

The healthcare services provided by NHS Trusts are derived from service agreements with purchasers that are of a short-term duration (a typical service agreement may have a duration of one year). Upon renewal of these agreements, the healthcare services provided by individual Trusts are likely to be revised, causing a corresponding amendment of the space use demands placed on supporting buildings in the short-term. As it is uneconomic to frequently implement market testing procedures facilities management services contracts are usually let by NHS Trusts with a medium term duration of between three and seven years (Department of Health, 1996). Outsourced facilities management organisations must therefore translate continually changing performance-orientated space use demands of building users within the duration of their contractual responsibility for supporting buildings. The varying timescales of these space use drivers are illustrated in Figure 1. 


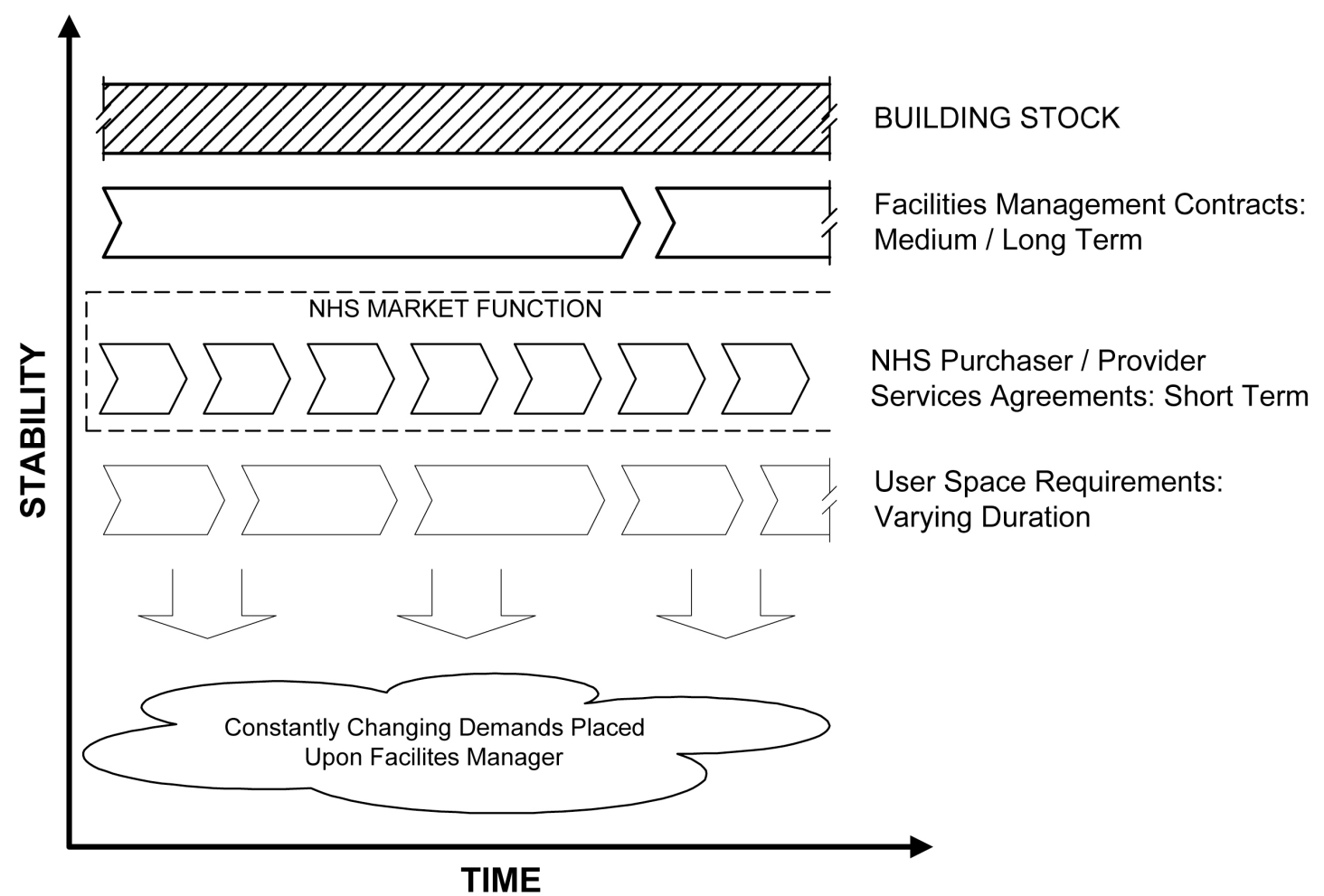

Figure 1: The Duration of Relationships Between the Building and Organisational Responsibilities for its Operation

As NHS Trusts seek to become responsive to and effective in their operating market environment it is envisaged that their focus on the short-term will increase. The buildings provided to support their activity must therefore be capable of readily accommodating changes in the use of their constituent spaces. The construction industry must respond by creating new buildings that are adaptable, allowing their operating facilities managers to readily respond to changing space use demands throughout their life. New methods of increasing the adaptability of existing buildings must also be developed for use by facilities managers.

\section{Facilities Management Function in Response to the Demands of NHS Space Users}

As built facilities supporting NHS function typically comprise the second largest element of NHS expenditure after personnel (Fitton, 1995) it is essential that these assets are effectively managed. Both outsourced and in-house facilities managers must accurately translate building user (i.e. patient or medical staff) demands, that are typically non-technical and performance orientated, into practical space orientated solutions.

Effective facilities management is particularly necessary in the context of buildings developed for use by the NHS Trusts using the Private Finance Initiative, where managerial responsibility for whole building operation is outsourced via use of performance specification. The need for effective facilities management in $\mathrm{PFI}$ projects is demonstrated by the common presence of facilities management organisations in the private sector consortiums developing these projects. In such projects, there is a need to create adaptable buildings to minimise the risk exposure of private sector building operators as well as meeting the changing space use demands of users. 


\section{The Creation of Adaptable Serviced Building Spaces}

To assist facilities managers develop solutions to building users' space performance requirements, new building utilisation techniques must be developed to endow these traditionally more inert assets with greater adaptability. The need for greater adaptability and flexibility in use is particularly relevant to more highly serviced building spaces where the complexity and cost of construction of associated services installations may impede their adaptation. The emerging trend for businesses to focus on short-term function, together with the increasing extent and complexity of services in buildings, is expected to necessitate that facilities managers develop an ability to flexibly utilise and adapt serviced building spaces.

One possible technical solution to this need for building flexibility is the design, manufacture and deployment of services components that are capable of being reused. The construction of new buildings incorporating such reusable services components will allow facilities managers to readily adapt serviced space use throughout their life. In addition, incremental application of these reusable services components to existing building services installations will progressively increase their adaptability. As such reusable components will have been installed for a short period and have the potential to be reused they are likely to possess a much higher residual value than those components currently recovered from use and sold for their scrap value.

The consequences of implementing reusable services components are likely to affect their design, procurement and method of application to buildings as well as influencing the roles performed by various organisations. To learn how component reuse could be developed in the construction industry it is prudent to review the successful reuse processes of other industries.

\section{Analysis of Reuse in Other Industrial Sectors}

Other industries have reused for many years. Analysing the reuse practices of these other sectors provides an opportunity to identify process characteristics that are suitable for adaptation by the construction industry. The observed diversity in the reasons for reuse as well as reused item size and value illustrates that reuse can be viable in a variety of circumstances.

The oil industry commonly reuses offshore accommodation modules and prefabricated modular engineering plant items. Reuse in this sector occurs for a number of reasons. First of all, the opportunity cost of leaving a space on an offshore installation occupied with a functionally redundant module provides an incentive for reuse. Secondly, the high value and durability of modules facilitates their reuse. The residual value of these items is high enough to finance their logistically difficult recovery from offshore installations for onshore repair or remanufacture prior to reuse. Finally, once the components have been returned onshore, it becomes possible to offer them for sale to other operators for reuse.

The office equipment industry demonstrates how the procurement process can facilitate reuse. Organisations wishing access to photocopying services will lease a photocopier from its original manufacturer. As the lease is specified in terms of machine output (i.e. performance), reused components can be utilised. A copier leased from Xerox will, for example, will contain a number of components or modules recovered from previous copiers returned when their lease expired. 
By subjecting these components to "signature analysis" their performance and anticipated future life can be estimated to determine suitability for reuse.

The reuse of high value mechanical components in the aircraft industry and low value mechanical components in the automobile industry is characterised by the existence of an installed user base of identical components that do not change throughout the life of the product to which they are applied, that is, the life of a particular aircraft or automobile model. In the automobile industry reuse of components such as starters, alternators, gearboxes and entire engines is facilitated by large scale remanufacturing processes where economies of scale make reuse economically viable. Aircraft component reuse is governed by mandatory certification requirements that ensure air-worthiness. As these components are maintained to the exacting requirements demanded by certification throughout their life, upon reaching the maximum permitted flying hours they may be sold for reuse in other industries. The offshore oil industry, for example, has used aircraft engines as power sources in large generators.

Comparison of reuse in the aircraft and automobile industries illustrates the circumstances under which a need to certify reused component fitness for purpose arises. In the aircraft industry, where the consequences of component failure are potentially catastrophic, there is mandatory third party (the UK Civil Aviation Authority) certification of components. In the automobile industry where the potential consequences of component failure are less severe, the provision of warranties equivalent to those provided with new components is sufficient to facilitate reuse. It remains to be established at what point between these extremes differing types of reused building services component will lie. It is noted, however, that certification requirements already exist in the maintenance of certain components.

It is concluded from observation of reuse in other industrial sectors that it may be possible to develop reusable services components to create flexible serviced spaces. Correctly developed and utilised, reusable services components will provide the construction industry with a means to satisfy client demands for adaptable buildings by enabling facilities managers to effectively coordinate space use in the resultant more adaptable buildings. If proven successful in the healthcare sector, where buildings are extensively and complexly serviced, reusable services components can be applied to the buildings supporting other industries.

Outwith the activities of individual organisations, the current reuse practices of the construction industry mainly comprise the recycling of raw materials, such as concrete or brick rubble, recovered during building demolition. In particular circumstances demolition can be a disassembly process (Halliday, 1996), but ultimately raw construction materials are recovered as current recycling practices tend to address a desire to minimise landfill charges. Limited examples of the reuse of services components that have not been specifically designed to be reusable, rather than materials, can be found in the remanufacture of compressors, pumps, fan motors and lift installations.

The reuse of services components also addresses the demands of clients who operate environmental management systems in accordance with the requirements of BS 7750 or the ISO 14000 series (Griffith, 1997). Recovery of functionally redundant components that would 
otherwise be disposed of reduces the quantity of the waste stream generated throughout the life of the building thereby reducing its environmental impact.

The above analysis illustrates that reuse can be viable in a variety of circumstances and is accepted as a valid business practice by a number of industrial sectors. It is observed that the benefits of reuse vary with the nature of its application. The benefit of increased flexibility in the use of spaces whose associated services installations incorporate reusable components is considered appropriate justification for this proposed application of reuse principles to construction.

\section{The Implementation of Reusable Building Services Components}

The design of reusable services components must incorporate attributes considered conducive to the implementation of reuse. While these attributes are yet to be identified, the current understanding of areas requiring consideration are illustrated in Figure 2 and can be summarised as follows.

- design for remanufacture; to assist the performance of component remanufacture to ensure fitness for purpose upon reuse.

- design for disassembly; considering both deconstruction of the component from the building and deconstruction of the component into its constituent parts once outside of the building.

- standardisation; of the size and weights of components and of their connection locations and physical format.

- modularisation; development of component designs to accommodate greater reconfigurablity, possibly facilitating the exchange of parts or modules between components.

- prefabrication; via the provision of systems of components instead of individual components. 


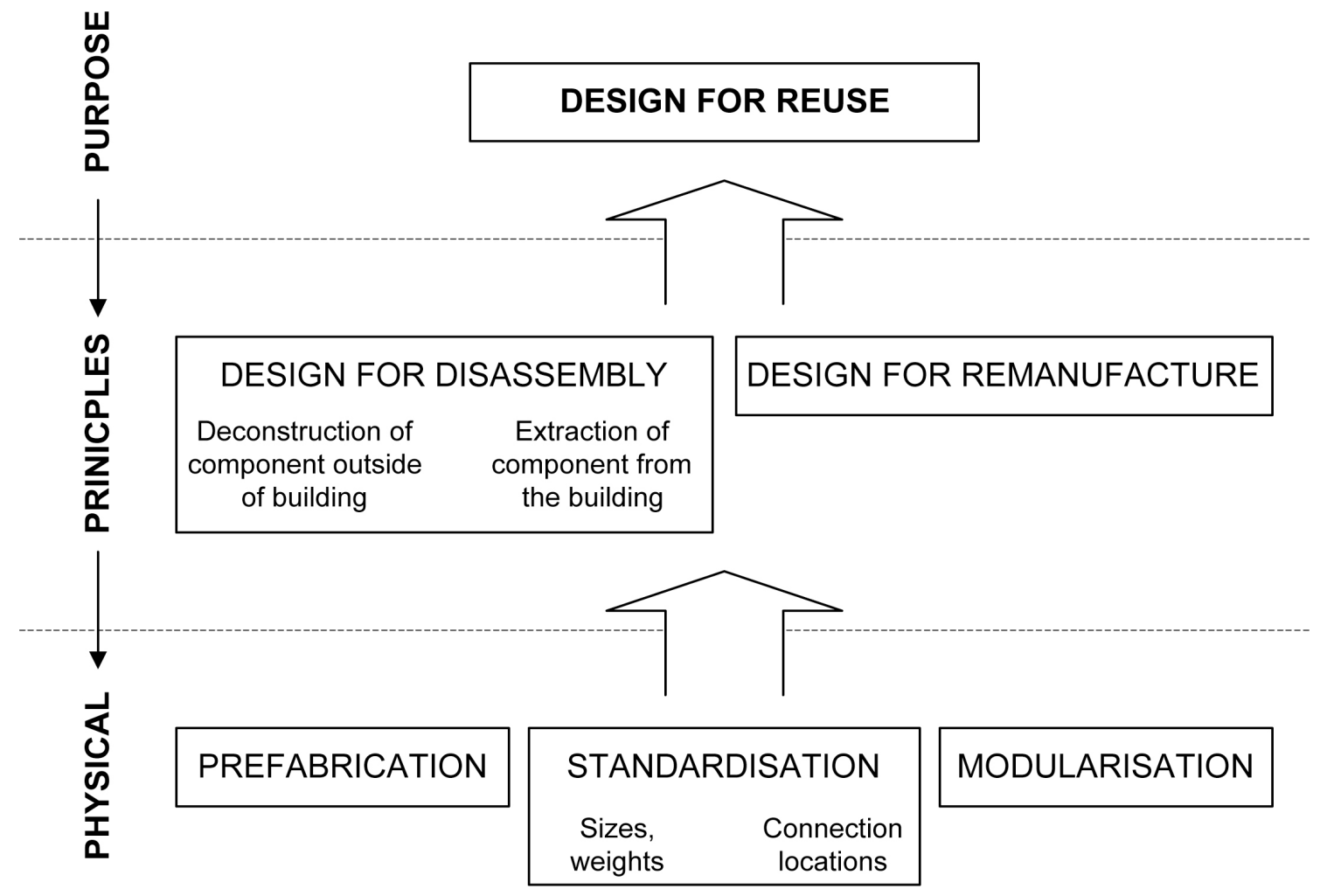

Figure 2: The Design Requirements of Reusable Services Components

Building services component procurement methods must also be revised to accommodate reuse. Analysis of reuse in other industries has identified that performance specifications can be used to implement reuse. It is proposed that recovered components undergo a remanufacturing or reconditioning process to ensure their fitness for purpose upon reuse. As this process ensures that reused components are functionally identical to their new counterparts, they will satisfy the functional output requirements of such performance specifications.

Extending the use of performance specifications to define the functional output required from entire buildings may create a role for the skills currently possessed in embryonic form by the consortiums of private sector companies involved in the private finance initiative. It is envisaged that these consortiums could evolve into a new form of construction industry member, providing clients with a means to secure access to supporting buildings through payment of a single revenue stream. As this envisaged use of performance specifications to procure the support of whole buildings isolates users from operational responsibility, it is likely that more opportunities for the reuse of components will be created throughout the whole building, rather than being restricted to the individual systems currently procured in this manner. Provided that this does not comprise the functional output of the building, the user need not be specifically aware that reusable components are being utilised. 


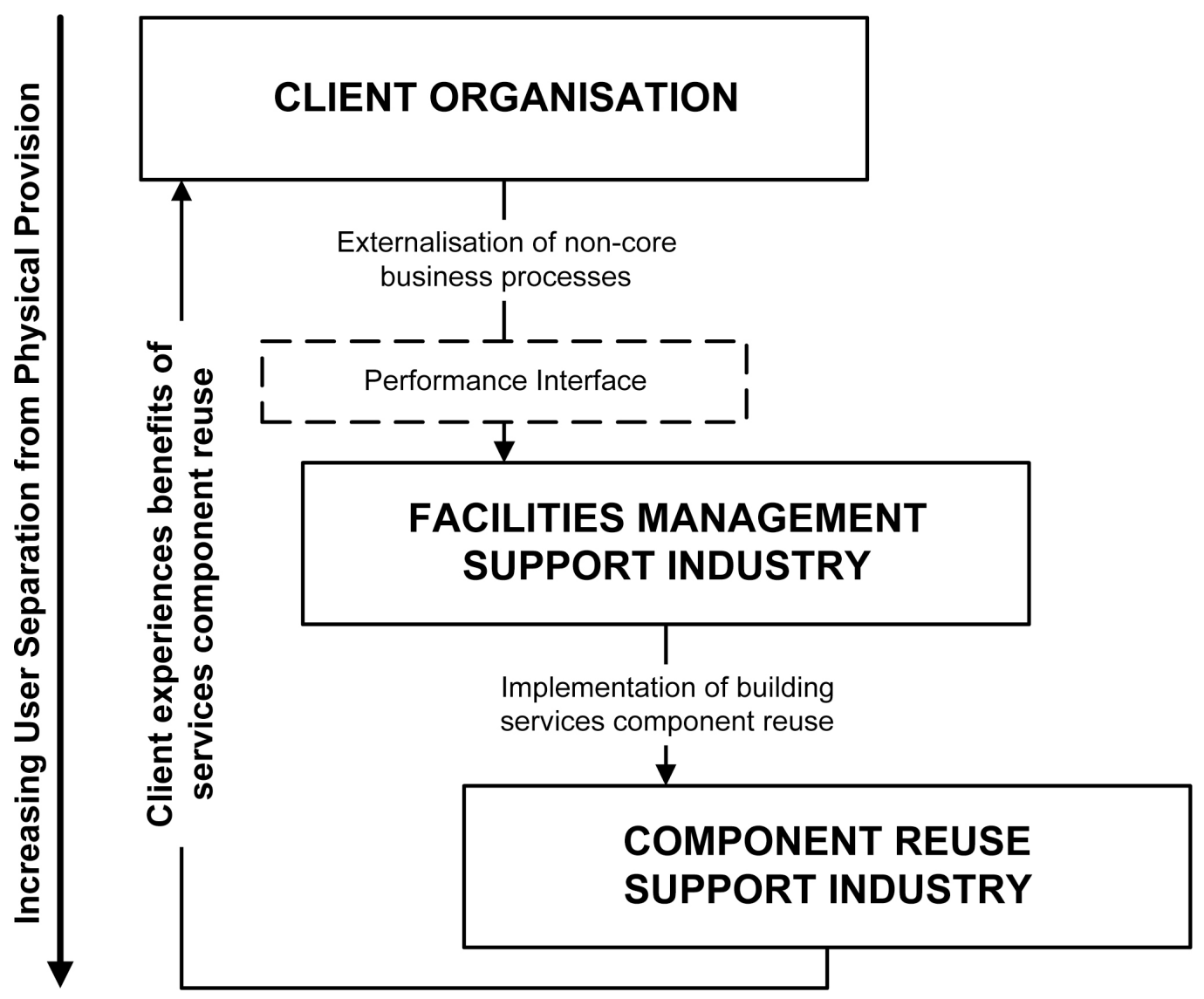

Figure 3: The Cascading Relationship Between Clients, Their Facilities Management Organisation and the Services Component Reuse Industry

To support the reuse of building services components a new industrial sector may emerge to undertake the remanufacture or reconditioning of recovered reusable services components to ensure their fitness for purpose upon reuse. Membership of this industry could comprise original component manufacturers, maintenance contractors, or new entrants. The interface between this support industry, organisations selling functionally redundant services components to it (to recover their residual value) and organisations purchasing reconditioned components from it will most likely comprise an open market function. Figure 3 illustrates how building users (clients) are likely to become isolated from the function of this support industry as their outsourced facilities management organisation provides a performance interface to the buildings supporting their core function.

\section{Conclusion}

It has been established that, as businesses focus on performing core function in the short-term, they require greater adaptability from supporting buildings. The skills of external facilities management organisations are often used to co-ordinate the provision of buildings to support performance of this core function.

It is considered that the development and utilisation of reusable building services components will enable facilities managers to increase the flexibility and adaptability of buildings and reduce the cost of adapting their constituent serviced spaces. The increased building flexibility derived 
from the introduction of reuse in this manner will also benefit users as their supporting buildings will more readily accommodate adaptation to suit their continually changing space needs.

By demanding flexible and adaptable buildings, construction industry clients can stimulate development of reusable services components. By using performance specifications to procure services installations instead of specifically identifying individual components in traditional specifications, building services system designers can create a procurement environment conducive to the utilisation of reusable components by installing contractors.

By utlising appropriate aspects of standardisation, modularisation and prefabrication design principles component manufacturers will be able to develop services components to be more reusable by providing them in a packaged format. Such components will be designed to be applied and removed to and from buildings while readily accommodating their remanufacture for reuse.

Installing contractors may have to revise the role they perform when installing new or adapting existing services installations as these organisations are most likely to recover components for reuse. These organisations may implement reusable components in their interpretation of performance specifications derived by system designers.

Initially, there will be a need for research to demonstrate that revision of performed roles may be necessary to facilitate the implementation of services component reuse. An education process must take place to illustrate the potential benefits of such reuse to the construction industry. It is envisaged that this education process will instigate revision of the roles performed by the above groups.

\section{The Research Project}

It is proposed that the current and anticipated future business environment, with its focus on the performance of core function in the short-term, necessitates development of reusable building services components to create more readily adaptable buildings. To study this proposition, the Department of Building Engineering and Surveying, Heriot-Watt University, Edinburgh has received funding from the EPSRC to carry out a pilot study of construction industry attitudes towards component reuse. Having established reuse to be a valid business practice, this project seeks to determine the economic viability and technical feasibility of these proposals.

It is anticipated that the outcome of this research project will demonstrate the viability and industrial acceptance of the proposed development of reusable building services components and their associated reconditioning support industry. The envisaged continuance of the business trend towards externalisation of non-core function and increasing focus on performing core processes in the short-term is likely to create a business environment increasingly conducive to the implementation of these research proposals. It is likely that further investigation of reuse will be required to derive practical implementation guidance for use by building designers and component manufacturers. The services component reuse implementation techniques developed by such subsequent research studies may eventually provide a means to 
develop buildings that address the requirements imposed upon them by the dynamic business environment in which construction industry clients operate.

\section{References}

Alexander, K. (1993) "The Emergence of Facilities Management in the United Kingdom National Health Service." Property Management, Vol. 11, No. 1, pp. 31-41.

Anon. (1993) The Future of European Health Care, Andersen Consulting, London.

Department of Health (1989) Working for Patients, Cm. 555., HMSO, London.

Department of Health (1996) Re-engineering the Facilities Management Service (Health Facilities Notes, No. 16), HMSO, London.

Fitton, P. (1995) "Resource Management in NHS FM", in Alexander, K. (1995), Facilities Management 1995, Blenheim Business Publications, London.

Griffith, A. (1997) Environmental Management in the Construction Process (Construction Papers, No. 75), The Chartered Institute of Building, Ascot.

Halliday, S. P. (1996) Environmental Code of Practice for Buildings and their Services: Case Studies, Bracknell, BSRIA.

Pearce, I. (1989) "The NHS Estate Healthy Prospects." Estates Gazette, Vol. 16, No. 8950 (December), pp. 38-39.

Pitt, T., Griffith, G (1995) "Space Utility in Healthcare Properties - A Facilities Management Approach", in Meban, A.G. et. al. (Ed.), Financial Management of Property and Construction, University of Ulster, Jordanstown, pp. 293-301.

Willis, J. (1992) "The Inner Game of Facilities Management." Facilities, Vol. 10, No. 10, p. 8-10. 